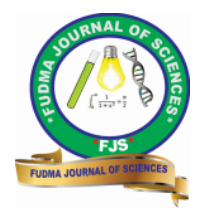

FUDMA Journal of Sciences (FJS)

ISSN online: $2616-1370$

ISSN print: 2645 - 2944

Vol. 4 No. 3, September, 2020, pp $476-480$

DOI: https://doi.org/10.33003/fjs-2020-0403-338

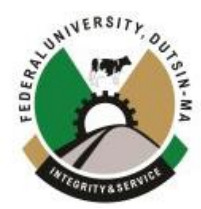

\title{
SYNTHESIS AND CHARACTERIZATION OF ZSM-5 ZEOLITE USING ETHELINEDIAMMINE AS ORGANIC TEMPLATE: VIA HYDROTHERMAL PROCESS
}

\author{
Abubakar, A. and Abubakar, S. \\ Department of Pure and Industrial Chemistry, Umaru Musa Yar'adua University, Katsina State, Nigeria
}

Corresponding Author's email: abduljozy79@gmail.com

\begin{abstract}
Zeolite can be synthesized from different substances but because of the environmental issues researchers have currently drawn their attention to cost effective and eco-friendly materials that can be used in the synthesis of various zeolites. Kaolin is one of these materials because of their nonhazardous and easy handling property. The uniqueness properties of the material gives it wide range of applications in different fields such as gas separation, adsorption and catalysis.. ZSM-5 Zeolite was prepared by addition of (ethylenediamine) as organic template. This experiment was conducted at the optimum conditions at $1600 \mathrm{c}$ for a period of $44 \mathrm{hr}$. Zeolite synthesized from Kaolin is also a crystalline micro porous aluminosilicate solid consisting of pores and routes of a molecular size. The synthesized material was found to have high $\mathrm{SiO} 2$ content of $42.95 \%$ and the alumina content of $2.65 \%$ which gives the $\mathrm{SiO} 2 / \mathrm{Al} 2 \mathrm{O} 3$ ratio of 16.2 .In order to obtain a comprehensive picture of morphology of the synthesized material, spectroscopic analysis were performed sing X-ray powder diffraction (XRD) shows peaks at $2 \theta=7-9^{\circ}$ and $22-25^{\circ}$, which correspond to the specific peaks of ZSM-5. Fourier-transform infrared spectroscopy (FTIR) which shows the absorption band near $450 \mathrm{~cm}-1$ is due to the T-O bending vibrations of the $\mathrm{SiO} 4$ and $\mathrm{AlO} 4$ in tetrahedra. scanning electron microscope (SEM) in this zeolite was crystallized in spherical to cubical shape.
\end{abstract}

Keywords: ZSM-5, structure directing agent, template.

\section{INTRODUCTION}

Kaolin is one of the low cost and available silica rich raw materials used in zeolite synthesis. Literatures reported that the essential components of a material to qualify for zeolite synthesis are silicon oxide $\left(\mathrm{SiO}_{2}\right)$ and aluminum oxide $\left(\mathrm{Al}_{2} \mathrm{O}_{3}\right)$ (Querol et al., 2001). The synthetic zeolites obtained by harnessing kaolin indicates that the material has a great potential as a cost-effective, eco-friendly solution that can be used efficiently as heterogeneous catalysts.

Zeolite was a Greek word meaning "boiling stone" because when heated water was released (Cejka, et al., 2007). Over forty natural zeolites are reported to be in existence as they formed naturally. Tschemich et al., 1992, reported that the first zeolite was discovered in 1756. Natural zeolite consist of large amount of impurities and their surface areas is low which limit their catalytic activity and absorption capability, as such this narrow their applications. Researchers begin to develop synthetic zeolites, like ZSM-5 in the 1970s and discovered that it has very efficient catalytic chemical conversion, mainly in isomerization, alkylation, and aromatization process (Ren et al., 2017). Since then zeolites became widely used in various applications (Auebach, et al., 2003). Therefore, further research was carried out and many synthetic zeolites were developed. International Zeolite Association reported that, there are now 231 known zeolite framework structures. Zeolite Socony Mobil-five (ZSM-5) is a crystalline micro porous aluminosilicate substance consists of $\mathrm{SiO} 4$ and $\mathrm{AlO} 4$ tetrahedral with pores and channels of a molecular size. The building block of ZSM-5 is a three-dimensional framework and the structure units contain eight five-member rings with uniform pore size and it has high thermal stability, many acid sites, high selectivity, well adsorption property etc. It has reported that this type of zeolite has very important chemical properties, which makes the material very useful in many industries such as selective absorbent, ion-exchange resin, and high activity catalyst (Kusuma, et al., 2013).

ZSM-5 Zeolite can also be prepared with the addition of a templating agent such as tetrapropylammonium (TPA) bromide, iodide, or hydroxide (Argauer et al., 1972), mono or polyhydric alcohols with ammonia (Planck et al., 1980) or diamines such as ethylenediamine (ED) or hexamethylenediamine (Deane et al., 1977). Systematic synthesis of zeolite was first established by Richard Barrer and Robert Milton in the 1940s by investigating the conversion of known mineral phases at high temperatures $\left(70-270{ }^{\circ} \mathrm{C}\right)$ (Auerbach et al., 2003). These materials were later determined to be zeolite ZK-5 with a KFI structure. The synthesis conditions were later optimized by Milton and co-workers in late 1940s when zeolites $\mathrm{A}, \mathrm{X}$ and $\mathrm{P}$ were produced hydrothermally at low temperature (i.e. below $100^{\circ} \mathrm{C}$ ) under autogenous pressures. Significant developments in zeolite synthesis then occurred over the few decades particularly when quaternary ammonium cations were introduced as structure directing agent for the formation of zeolites. Following the first successful synthesis of high silica zeolite, zeolite beta with $\mathrm{Si} / \mathrm{Al}$ ratio ranging from 5 to 100 , the ZSM-5 zeolite was synthesized using tetrapropylammonium cation $\left(\mathrm{TPA}^{+}\right)$ (Argauer et al., 1972). The high cost of TPA as compared with other templating agents makesthe research to alternatively used ethylene diamine (ED) to serve as structure directing agent as it decrease the cost of ZSM-5 production. 
Jiang, et al., 2014, as successfully synthesized ZSM-5 hydrothermally in acid solution using natural zeolite Palygorskite with TPABr as template at $180{ }^{\circ} \mathrm{C}$ for 48 hours. ZSM-5 zeolite has also been successfully synthesized from natural alumina-silica in alkaline solution through sub molten systems (Yue et al., 2014). In this work, we focused on synthesis of ZSM-5 zeolite using silica gel as sources of silica and natural Kankara kaolin as a source of alumina. Liu et al., 2015, reported that prior to the synthesis; depolymerized zeolite framework of ZSM-5 was carried out through sub molten system in alkaline solution at temperature $523 \mathrm{~K}$. However, prior to our synthesis beneficiation was carried out then followed by calcinations. Synthesis of ZSM-5 can be carried out through single template methods using tetrapropylammoniumhidroxyde (TPAOH) as structure directing agent (SDA) (Lupulescu, et al., 2012). Moreover, in the some researches Ethylene diamine was used as structure directing additive while it was used also by some researchers as a template for borosilicate and boroaluminosilicate (Perego et al., 2003; Kester et al., 2018).

\section{MATERIALS AND METHODS}

The chemical used includes silica gel Fluka (Merck), ethylenediamine (BDH ltd England), concentrated sulphuric acid (Pure chem. product ltd), sodium chloride (Pure chem. product ltd), local kaolin (Kankara, Katsina State, Nigeria).The materials and equipment used includes Autoclave STI9T (Dixon's Surgical instrument), Scanning Electron Microscope (Model 440i), FTIR Spectrophotometer Cary 630 (Agilent Tech), XRF Rigaku ZSX-100 etc.

\section{Pretreatment of Kaolin}

The kaolin is obtained from mining site in Kankara Local Government and preheated at $600-700^{\circ} \mathrm{C}$. The amorphous preheated metakaolin phase was washed with acid to further remove anypossible impurities (Khatamian, et al., 2007).

\section{Synthesis of ZSM-5 Zeolite}

ZSM-5 was synthesized hydrothermally. The following reagents were used for the synthesis of zeolites; the obtained kaolin was used as alumina source, Silica gel as silica source and ethelendiammine as structure directing agent.

Two solutions were prepared separately as follows; $1.5 \mathrm{~g}$ of sodium hydroxide, 6.03 gof silica gel, $3 \mathrm{ml}$ of ethelenediammine were added to $15 \mathrm{ml}$ of distilled water and the mixture was stirred for 1 hour using magnetic stirrer to get solution A (stirred at 2,600 revelation per minute).In another container, $0.6579 \mathrm{~g}$ of metakaolin was mixed thoroughly with $15 \mathrm{ml}$ of distilled water and $1.5 \mathrm{ml}$ of concentrated sulfuric acid was added to get solution $\mathrm{B}$. The mixture of solution $\mathrm{A}$ was added to solution B; the mixture was stirred until a gel was formed. The stirring continued for another $2 \mathrm{hrs}$ until a homogenous mixture is obtained. The mixture was transferred to a stain-less steel autoclave with $70 \mathrm{~mm}$ long tube having $41 \mathrm{~mm}$ and $5 \mathrm{~mm}$ thickness. The sealed autoclave with Teflon internal vessel was heated with the autogenously pressure in an air oven maintained at $433 \mathrm{k}$ for $44 \mathrm{hrs}$.

\section{RESULT AND DISCUSSION}

Table 1: XRF result of the synthesize ZSM-5

\begin{tabular}{|l|l|l|l|l|l|l|l|l|l|l|l|}
\hline FORMULA & $\mathrm{SiO}_{2}$ & $\mathrm{SO}_{3}$ & $\mathrm{Na}_{2} \mathrm{O}$ & $\mathrm{Al}_{2} \mathrm{O}_{3}$ & $\mathrm{MgO}$ & $\mathrm{CaO}$ & $\mathrm{P}_{2} \mathrm{O}_{5}$ & $\mathrm{~K}_{2} \mathrm{O}$ & $\mathrm{Fe}_{2} \mathrm{O}_{3}$ & $\mathrm{Cl}$ & $\mathrm{TiO}_{2}$ \\
\hline $\begin{array}{l}\text { COMPOSITI } \\
\text { ON (wt\%) }\end{array}$ & 42.95 & 42.41 & 7.5 & 2.65 & 1.1 & 1.08 & 0.90 & 0.51 & 0.42 & 0.28 & 0.12 \\
\hline
\end{tabular}

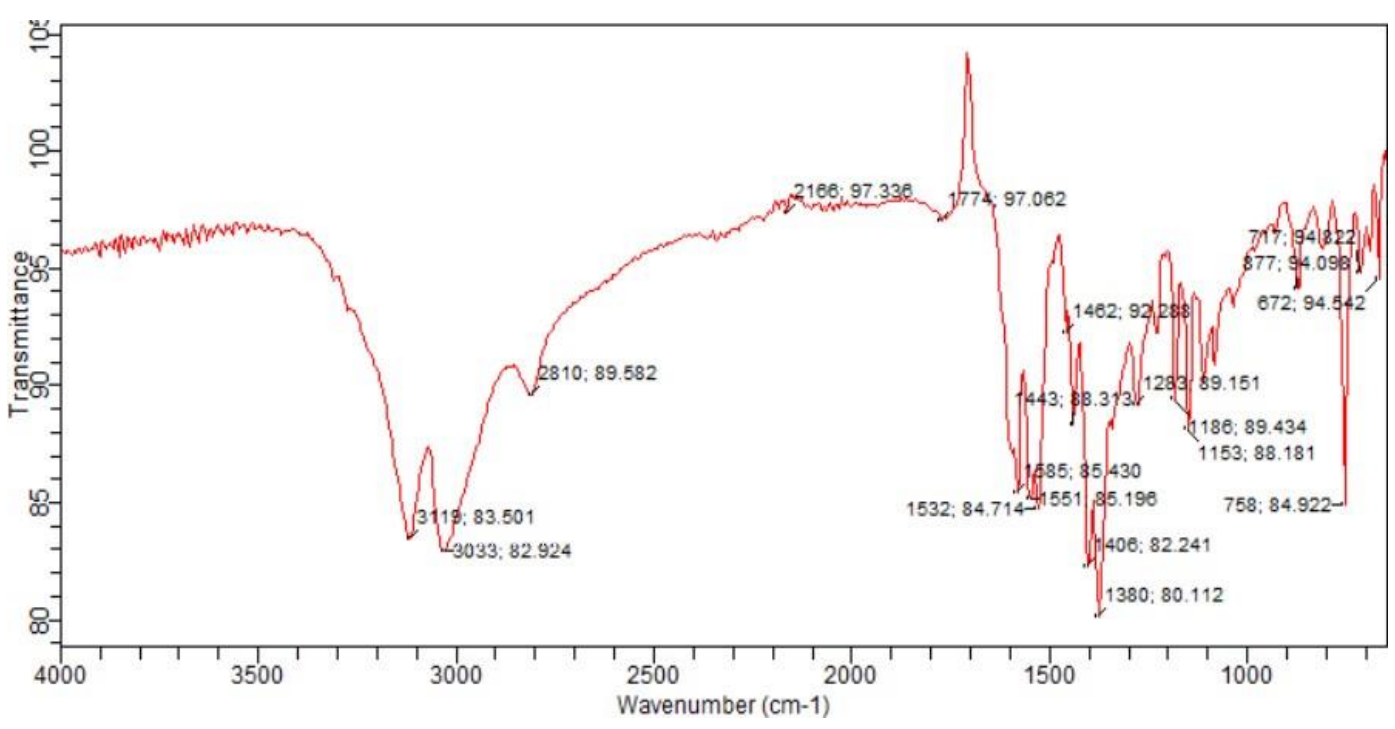

Fig.1: Show the FT-IR analysis of the synthesized ZSM-5 zeolite. 


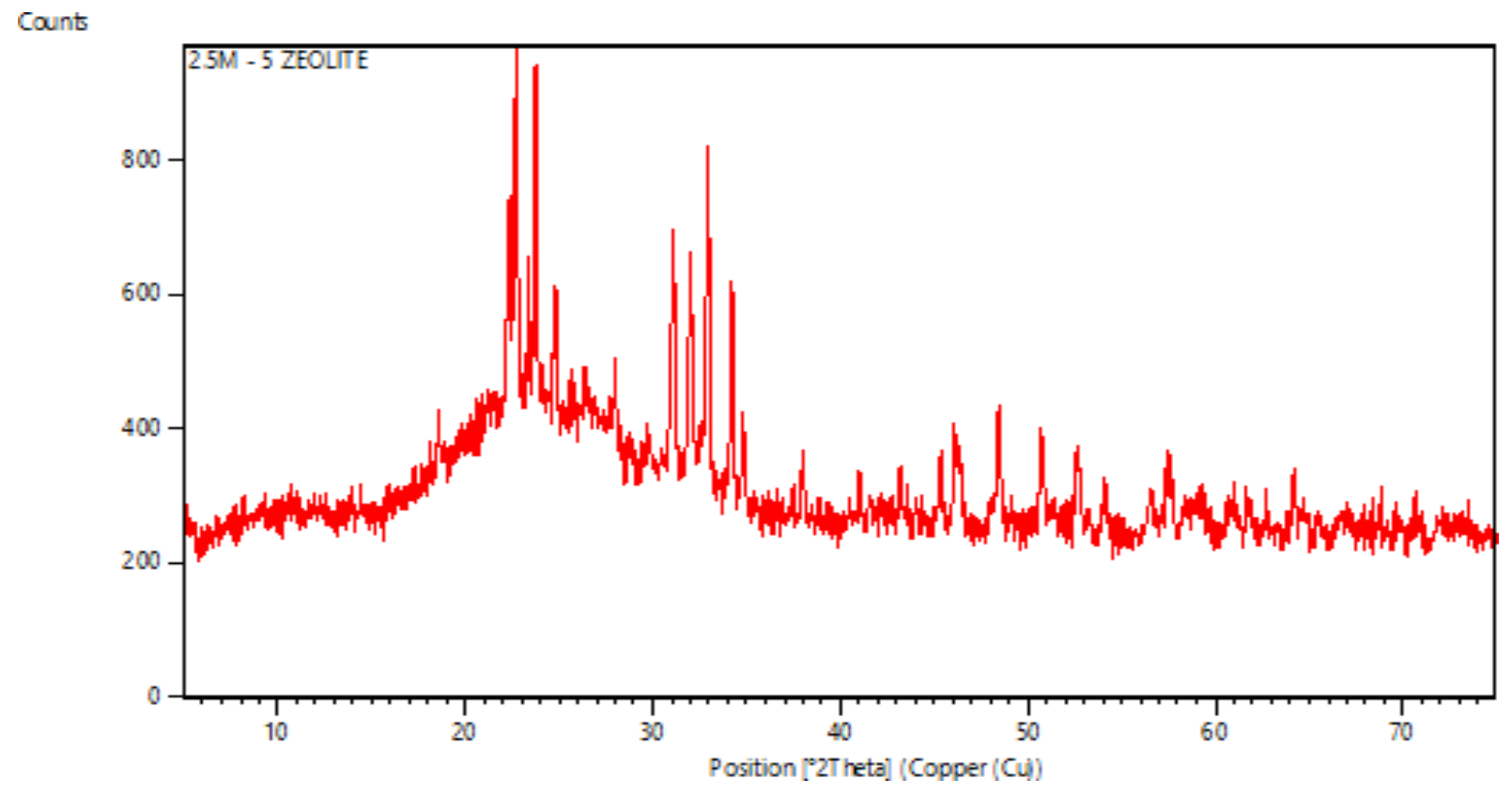

Fig.2: Shows the XRD result of synthesized ZSM-5 zeolite. 


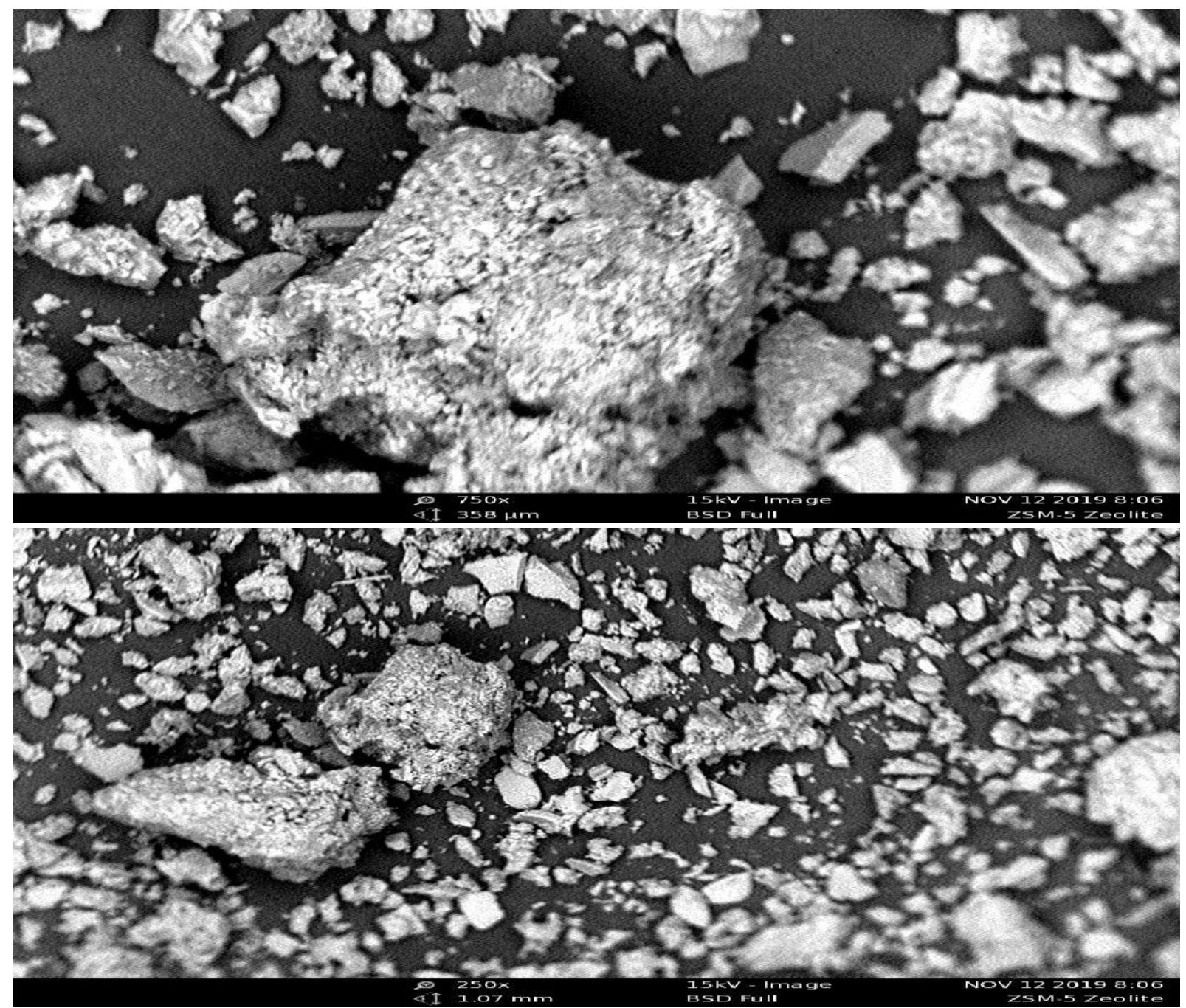

Plate: 1: Shows the SEM micrographs of ZSM-5 X750 and X250

It was observed from Table 1, that the kaolin composed of high $\mathrm{SiO}_{2}$ content of $42.95 \%$. $\mathrm{Na}_{2} \mathrm{O}$ and $\mathrm{SO}_{3}$ constitute 7.5 and $42.41 \%$ respectively, while the alumina content was found to be $2.65 \%$. Those are the major chemical composition of most common zeolites. The $\mathrm{Si} / \mathrm{Al}$ ratio is an important factor in Zeolite synthesis, the crystal size of the ZSM-5 zeolite decreases with increasing the $\mathrm{SiO}_{2} / \mathrm{Al}_{2} \mathrm{O}_{3}$. In this work, the $\mathrm{SiO}_{2} / \mathrm{Al}_{2} \mathrm{O}_{3}$ ratio was 16.2 . After crystallization the ratio reduces remarkably and this may be due to alkaline nature medium of the gel during synthesis with $\mathrm{pH}$ range of 10-11. Moreover, alkalinity enhance dissolving more silica in the liquid phase and therefore, less silica was usually left and become incorporated into the crystalline solid phase; so a considerable decrease in the $\mathrm{Si} / \mathrm{Al}$ ratio takes place after crystallization.

The FT-IR spectra of the synthesized zeolites were recorded in the range $4000-400 \mathrm{~cm}^{-1}$ Figure 1.0. The Figure shows infrared spectra of the synthesized zeolite at $160^{\circ} \mathrm{C}$ using ethelendiammine as SDA. In the zeolite sample the fundamental vibrations of $\mathrm{T}(\mathrm{Si} / \mathrm{Al}) \mathrm{O} 4$ tetrahedra of the zeolite framework has been observed in the region 400-1300 cm-1. Bands around 790, 1080 and $1219 \mathrm{~cm}-1$ are characteristic of $\mathrm{SiO} 4$ tetrahedron units as well. The external asymmetric stretching vibration near $1219 \mathrm{~cm}-1$ is due to the presence of structures containing four chains of five-member rings arranged around a two-fold crew axis, as in the case of ZSM-5 structure. The absorption band around $1080 \mathrm{~cm}-1$ is attributed to the internal asymmetric stretching vibration of Si-O-T linkage of zeolite ZSM-5. The absorption near $790 \mathrm{~cm}-1$ assigned to the symmetric stretching of the external linkages. The absorption band near $450 \mathrm{~cm}$ 1 is due to the T-O bending vibrations of the $\mathrm{SiO} 4$ and $\mathrm{AlO} 4$ in tetrahedra. The presence of absorption bands around 542 and $450 \mathrm{~cm}$ 1 are characteristic of the ZSM- 5 crystalline structure and the ratio of the intensities of these two peaks provides an approximate estimate of the degree of crystalline of a given zeolite sample and these are band characteristic of double ring, and is present specifically in ZSM-5 
zeolite.

The analysis of the X-ray diffraction patterns of ZSM-5 zeolite powder synthesized at $160^{\circ} \mathrm{C}$ using ethelinediammine as SDA with a crystallization time ( $44 \mathrm{hrs}$ ) was also carried out. From Figure 2, the result showed that crystallization is almost complete in less than 2 days. Therefore, increasing the crystallization time does not lead to better crystallization, but usually causes decomposition of the ZSM-5 crystal phase. The XRD pattern for ZSM-5(44 hrs) shows peaks at $2 \theta$ $=7-9^{\circ}$ and $22-25^{\circ}$, which correspond to the specific peaks of ZSM-5 according to ASTM data. As such No other peak could be observed. This indicates the high purity of product. The relative crystallinity of ZSM-5 was calculated based on the intensity of the peaks of angle $2 \theta=22-25^{\circ}$. Average crystal size measured about $21 \mathrm{~nm}$ for ZSM-5(44 h) by Scherer's equation $(\mathrm{D}=\mathrm{K}$ alpha 57.32 /beta $\cos \theta)$ from XRD peaks between $2 \theta=7-9^{\circ}$. The relative intensities are affected by the $\mathrm{Si} / \mathrm{Al}$ ratio and the distribution of these atoms in the unit cell. The synthesized sample of ZSM-5 show peaks at $2 \theta=7^{\circ}-9^{\circ}$ and $22^{\circ}-25^{\circ}$ that are characteristic of typical ZSM-5 zeolites.

The scanning electron micrograph (SEM) of ZSM- 5 was shown in Figure 2.The intensity of emission of both secondary and backscattered electrons is very sensitive to the angle at which the electron beam strikes the surface, i.e. to topographical features on the specimen. The crystallite size and shape is often influenced by different synthesis parameter (Szostak, 1992). The silica to alumina ratio, source of silica, alumina and templating agent, influences the crystal morphology (Guisnet and Gilson, 2002). From the image it can be seen that this zeolite was crystallized in spherical to cubical shape. The SEM photograph of the sample shows bigger crystal size which may increase the surface properties of the zeolites for different applications. No amorphous phase is observable, indicating high purity of the sample although slight agglomeration was observed.

\section{CONCLUSION}

A ZSM-5 zeolite was synthesized from amorphous metakaolin prepared by $\mathrm{H}_{2} \mathrm{SO}_{4}$ for the leaching of a kaolin mineral from Kankara mining, Katsina State Nigeria. The syntheses were conducted with organic template (ethelinediammine) as SDA type and the optimum condition was at temperature of $160^{\circ} \mathrm{C}$ for a period of $44 \mathrm{hrs}$. The synthesized material was found to have high $\mathrm{SiO}_{2}$ content of $42.95 \%$ and the alumina content of $2.65 \%$ which gives the $\mathrm{SiO}_{2} / \mathrm{Al}_{2} \mathrm{O}_{3}$ ratio of 16.2. The FT-IR spectra show some important absorption bands which indicate $\mathrm{Si}-\mathrm{O}-\mathrm{T}$ and $\mathrm{T}-\mathrm{O}$ linkages. the $\mathrm{X}$-ray diffraction patterns of the zeolite shows that crystallization is almost complete, while SEM micrographs implies that the sample crystallized in cubical shape with some agglomerations that occur.

\section{REFERENCES}

Argauer R.., J., and G.R. Landolt. (1972). Crystalline zeolite ZSM-5 and method of preparing the same, Google Patents.

Auerbach S.M., K.A. Carrado, and P.K. Dutta. (2003). Handbook of zeolite science and technology, CRC press

Cejka and Wichterlova. (2002). Sci. Eng.44375-421Acid-catalyzed synthesis of mono- and dialkyl benzenes over zeolites: active sites,
Zeolite topology, and reaction mechanisms Post- Synthesis Modifications on Zeolites for Improved Accessibility and Catalytic Performance.

Cejka J., H., Van Bekkum, A., Corma, and F., Schueth. (2007). Introduction to Zeolite Molecular Sieves, Elsevier.

Deane, R.L., Hickson, D.A., and Valyocsik, E.W. (1977). Belg. Pat. 886833 Desulfurization of Liquid Fuels.U.S.and Foreign Patent Applications.

Jiang J. C. Duanmu, Y. Yang, X. Gu, and J., Chen. (2014). Powder Technol. 251, 9-14 Y. Yue, et al. (2014). J. Catal. 319, 200-210

Kester, P. M., Miller, J. T.; and Gounder, R. (2018). Ammonia Titration Methods to Quantify Brønsted Acid Sites in Zeolites Substituted with Aluminum and Boron Heteroatoms. Ind. Eng. Chem. Res., 57,6673-6683

Khatamian, and M., Dolatyari. (2007). Asian Journal of Chemistry, 19, 5199-5210. Appl. Clay Sci. 115, 201-211

Lupulescu, A.I., Rimer, and J.D., Tailoring. (2012). Silicalite-1 Crystal Morphology with Molecular Modifiers. Angew. Chem. 2012, 124, 3401-3405.

M., Guisnet, and J. P., Gilson. (2002). Zeolites for Cleaner Technologies Imperial College Press, London.

N. C., van Laak. (2011). Thesis submitted to Universiteit Utrecht op gezag ISBN: 978-90- 393-5541-1

Perego, G., Bellussi, G., Millini, R., Alberti, A., and Zanardi, S. B. (2003). Molecular Sieves Crystallized in the Presence of Ethylenediamine. Part II: Crystal Structure of as-Synthesized B-MFI.Microporous Mesoporous Mater., 58, 213-223.

Planck, C.J., Rosinski, E.J. and Rubik. (1980). M.K. US Pat. 4199 566.

Querol, X., Umana, J.C., Plana, F., Alasuey, A., Lopez-Soler, A., Valreo, M.A., Domingo, M.J.and Garcea-Rojo, E. (2001).

Synthesis of zeolites from fly ash at Pilot plant scale: Examples of potential applications. Fuel, 80, p.857-865.

R. I., Kusuma, J. P., Hadinoto, A., Ayucitra, F. E., Soetaredjo, and S. Ismadji. (2013). Appl. Clay Sci. 74, 121-126.

Ren. J, C., Li, Y., Gou, B., Liu, H., and Xi. (2017). Appl. Surf. Sci. 392, 785-794.

Szostak, R. (1992). Handbook of molecular sieves. New York: Van Nostrand Reinhold.

Tschernich R.W. (1992). Zeolites of the World, Harbinger House.

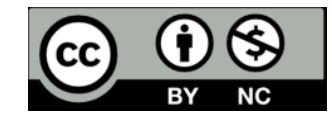

(C)2020 This is an Open Access article distributed under the terms of the Creative Commons Attribution 4.0 International license viewed via https://creativecommons.org/licenses/by/4.0/ which permits unrestricted use, distribution, and reproduction in any medium, provided the original work is cited appropriately. 